\title{
Artikel
}

\section{Licht aan het einde van de tunnel voor wensouders?}

\author{
Mr. N. van der Storm en mr. M.Q.M. Mosk*
}

Iedere eerste week van november is het de Europese week van de vruchtbaarheid. Ook dit jaar werd in de media op verschillende wijze aandacht gevraagd voor het thema vruchtbaarheid. Hiermee wordt getracht het feit dat niet iedereen op natuurlijke wijze zwanger kan worden, bespreekbaar te maken. Voor één op de zes mensen is een zwangerschap niet vanzelfsprekend. Voor enkelen is een zwangerschap zelfs uitgesloten, bijvoorbeeld wanneer dat om medische redenen niet mogelijk is. Dit betekent evenwel niet dat ook ouderschap is uitgesloten. Draagmoederschap kan voor deze mensen uitkomst bieden bij het vervullen van hun diepgewortelde wens om ouder te worden. Dat geldt voor heteroseksuele partners, maar ook voor partners van gelijk geslacht of alleenstaanden.

Tot voor kort heeft de Nederlandse wetgever draagmoederschap willen ontmoedigen. In de zomer van 2019 heeft het kabinet evenwel laten weten met een regeling voor draagmoederschap te zullen komen. In deze bijdrage gaan wij nader in op wat draagmoederschap inhoudt, tegen welke problemen je als (advocaat van) wensouders aanloopt en tot slot welke mogelijkheden het wetsvoorstel van het kabinet biedt voor de (rechts)praktijk.

\section{Draagmoederschap: wat is het juridisch kader?}

De wettelijke definitie van een draagmoeder is terug te vinden in artikel $151 \mathrm{~b}$ lid $3 \mathrm{Sr}$. Als draagmoeder wordt

\footnotetext{
Mr. N. van der Storm is advocaat \& mediator bij De Boorder Familie- en Erfrecht Advocaten \& Mediators. Mr. M.Q.M. Mosk is advocaat bij De Boorder Familie- en Erfrecht Advocaten \& Mediators.
}

aangemerkt de vrouw die zwanger is geworden met het voornemen een kind te baren ten behoeve van een ander die het ouderlijk gezag over dat kind wil verwerven, dan wel anderszins duurzaam de verzorging en opvoeding van dat kind op zich wil nemen. Opmerkelijk is dat niet Boek 1 BW (Personen- en familierecht) deze definitie kent, maar het Wetboek van Strafrecht. Reden hiervan is het feit dat Nederland, met uitzondering van een wettelijke bepaling die commercieel draagmoederschap verbiedt (art. 151b en 151c Sr), geen wetgeving over draagmoederschap kent. Niet-commercieel draagmoederschap is wel toegestaan, maar daarvoor ontbreekt het aan regels.

Draagmoederschap kan op twee manieren plaatsvinden: hoogtechnologisch of laagtechnologisch. Bij hoogtechnologisch draagmoederschap wordt een eicel met een zaadcel in het laboratorium bevrucht en wordt het embryo in de baarmoeder van de draagmoeder geplaatst. Vaak zijn de wensouders in deze situatie beiden de genetische ouders van het kind, maar dit hoeft niet. Hoogtechnologisch draagmoederschap kan ook via donorschap geschieden. Bij laagtechnologisch draagmoederschap wordt de eicel van de draagmoeder bevrucht, via de natuurlijke weg of via kunstmatige of zelfinseminatie. In dit geval is de draagmoeder de genetische moeder van het kind. Gebleken is inmiddels dat het ontbreken van wetgeving wensouders er niet van weerhoudt een draagmoederschapstraject te starten. Met de draagmoeder worden dan afspraken gemaakt over de zwangerschap en de periode na de geboorte. Wat echter niet altijd direct wordt overzien, is de vraag wie na de geboorte de juridische ouders van het kind zijn en wat ieders rechtspositie. In het onderstaande zal hier nader op in worden gegaan, waarbij ervan wordt uitgegaan dat de personen die betrokken zijn bij het draagmoederschaptraject allen over de Nederlandse 
nationaliteit beschikken en in Nederland woonachtig zijn.

\section{Juridisch ouderschap}

Voor het vaststellen van het juridische moederschap is niet relevant of de draagmoeder zwanger is geworden via de hoog- of laagtechnologische weg. Ex artikel 1:198 BW is namelijk de vrouw uit wie het kind is geboren juridische moeder van het kind (mater semper certa est). Dat het kind genetisch verwant is aan de wensmoeder of een eiceldonor maakt voor het bepalen van het juridische moederschap niet uit. In Nederland wordt op de geboorteakte dan ook altijd de draagmoeder als moeder van het kind vermeld. Wat betreft het bepalen van de rechtspositie van de overige betrokkenen, is relevant of de draagmoeder gehuwd is of een geregistreerd partner heeft.

Is de draagmoeder gehumd of heeft zij een geregistreerd partner, dan wordt de echtgenoot respectievelijk de partner bij de geboorte van het kind van rechtswege juridisch vader van het kind en overeenkomstig op de geboorteakte van het kind vermeld (ex art. 1:199 BW).

Voor de wensouders zijn vervolgens twee routes te bewandelen om het juridische ouderschap te verkrijgen. Allereerst kan er door een advocaat namens de wensouders een verzoek tot adoptie worden ingediend. Het gezag van de draagouders dient in dat geval wel eerst beëindigd te worden (art. 1:228 lid 1 sub g BW). Een verzoek daartoe aan de rechtbank dient door de Raad voor de Kinderbescherming te worden gedaan (art. 1:267 BW). Het criterium voor de beëindiging van het gezag van de draagouders luidt dat het kind zodanig opgroeit dat hij in zijn ontwikkeling ernstig wordt bedreigd en dat de draagouders niet in staat zijn binnen een voor het kind anvaardbare termijn de verantwoordelijkheid te dragen voor de verzorging en opvoeding ex artikel 1:266 lid 1 sub a BW. De term 'ongeschiktheid' leidt in de praktijk regelmatig tot vragen. $Z o$ vragen draagouders (die mogelijk zelf ook kinderen hebben) zich af of een dergelijke uitspraak ook gevolgen heeft voor hun 'geschiktheid' als ouders in het opvoeden van de eigen kinderen in hun gezin. Deze bepaling stuit dan ook bij zowel draag- als wensouders vaak op onbegrip. Veelal wordt tegelijkertijd met het verzoek om beëindiging van het gezag verzocht om de wensouders tot voogd te benoemen. Een andere route voor de wensouders om juridisch ouders te worden, is dat de bijzondere curator (art. 1:212 BW) bij de rechtbank een verzoek tot ontkenning van het vaderschap van de echtgenoot/partner van de draagmoeder indient (art. 1:200 $\mathrm{BW}$ ) en er tegelijkertijd door een bijzondere curator namens het kind verzocht wordt het vaderschap van de wensvader gerechtelijk vast te stellen (art. 1:207 BW). De wensvader kan in diezelfde procedure verzoeken tot overheveling van het gezag van de draagmoeder aan hem op grond van artikel 1:253c BW. Voor de (veelal) wensmoeder blijft vervolgens de optie van adoptie de enige juiste route om juridisch moeder te worden van het kind. ${ }^{1}$ Onzes inziens verdient de eerste route de voorkeur. De doorlooptijd ervan is namelijk over het algemeen korter en het in te dienen processtuk is minder complex, althans bevat minder verzoeken, wat economisch aantrekkelijker is voor de wensouders. Verder is van belang te vermelden dat bij de eerste route, wat betreft de gezagskwestie, in principe geen juridische bijstand van een advocaat vereist is.

Wanneer de draagmoeder ongehumd is, kan een van de wensouders het kind voorafgaand aan of na de geboorte bij de gemeente erkennen (art. 1:203/204 BW). Vervolgens wordt namens de wensouder die erkend heeft, door een advocaat, een verzoek bij de rechter ingediend om het gezag van de draagmoeder aan hem/ haar over te hevelen (ex art. 1:253c BW). Zodra deze gezagsbeslissing in kracht van gewijsde is gegaan, is het voor de andere wensouder mogelijk het kind te adopteren ex artikel 1:227/228 BW. Doorgaans worden deze twee verzoeken tegelijkertijd bij de rechtbank ingediend en behandeld.

Ongeacht of de draagmoeder gehuwd of ongehuwd is, wordt in de praktijk ook wel geprobeerd om het van rechtswege ontstane moederschap van de draagmoeder aan te tasten door middel van een verzoek tot ontkenning van het moederschap op de grond dat de draagmoeder niet de genetische moeder van het kind is. Vooralsnog worden dergelijke verzoeken afgewezen, ${ }^{2}$ omdat er geen wettelijke grondslag is in Nederland voor het ontkennen van het moederschap van de vrouw uit wie het kind is geboren. ${ }^{3} \mathrm{Er}$ is wel een wettelijke grondslag voor adoptie. Nadeel aan adoptie evenwel is dat deze geen terugwerkende kracht heeft.

Wanneer het kind voorafgaand of direct na de geboorte door een van de wensouders is erkend, staat het deze ouder vrij het kind na de geboorte mee naar huis te nemen. Wanneer het kind niet is erkend, dienen de wensouders formeel toestemming te vragen aan de Raad voor de Kinderbescherming om het kind in hun gezin op te nemen omdat het juridisch gezien (nog) niet hun eigen kind is en daarmee als pleegkind wordt aangemerkt. Zij dienen vervolgens de rechter te vragen hen met de voogdij te belasten ex artikel 442a Sr jo. 1:241 lid $3 \mathrm{BW}$. Na het kind één jaar in hun gezin verzorgd en opgevoed te hebben, kunnen de wensouders aan de rechter om het uitspreken van de adoptie vragen (art. 1:227/228 BW). De termijn van één jaar is met name bedoeld om de bestendigheid van de verzorging en opvoeding te kunnen beoordelen. Vaak gebeurt het echter dat de rechter coulant is in de toewijzing van het verzoek, ondanks dat de verzorgingstermijn van één jaar nog niet is voltooid. Als het kind genetisch afstamt van (ten minste een van) de wensouders en de wensouders

Ofwel voor de partner van gelijk geslacht van de wensvader

2. Zie o.a. Rb. Amsterdam 27 november 2019, ECLI:NL:RBAMS:2019: 8839 en Rb. Den Haag 27 juni 2019, ECLI:NL:RBDHA:2019:7676.

3. Dit is anders in de situatie dat er een verzoek tot ontkenning van het moederschap wordt ingediend namens een duomoeder die van rechtswege door het huwelijk het moederschap heeft verkregen (art. 1:202a BW). 
het kind vanaf de geboorte verzorgen en opvoeden, wordt het vasthouden aan de termijn niet verenigbaar geacht met het bepaalde in artikel 8 jo. $14 \mathrm{EVRM}^{4}$ en de verzorgingstermijn losgelaten. Dit is in lijn met de jurisprudentie van het $\mathrm{EHRM}^{5}$ en the advisory opinion van 10 april 2019. ${ }^{6}$ Het EHRM acht het namelijk in het belang van het kind dat het een juridische afstammingsband heeft met de personen die hem verzorgen en opvoeden, zelfs indien tussen hen geen genetische band bestaat. Daarbij acht het EHRM het in het belang van het kind dat de periode vanaf de geboorte van het kind totdat de juridische band met de wensouders is gevestigd, zo kort mogelijk is, zodat het kind minder lang in een onzekere positie verkeert, waarbij omstandigheden als (rechtmatig) verblijf bij de wensouders, nationaliteit en erfrecht een rol kunnen spelen.

\section{Uitdagingen in de praktijk}

In de praktijk gebeurt het lang niet altijd dat wensouders juridisch advies inwinnen voordat de draagmoeder zwanger wordt. Een terugkerende situatie is dat wensouders hebben gekozen voor een draagmoeder in het buitenland en dat zij op het moment dat zij naar Nederland willen afreizen en/of het kind in Nederland willen inschrijven in vervelende situaties terechtkomen. In sommige landen - waaronder Oekraïne - worden de wensouders direct als de juridische ouders aangemerkt, waardoor zij als wensouders op de geboorteakte van het kind worden vermeld. Dit is in strijd met de Nederlandse wetgeving omdat het niet voldoet aan het mater semper certa est beginsel. Daarnaast kan het zo zijn dat de buitenlandse draagmoeder gehuwd was, wat betekent dat conform Nederlands recht de echtgenoot van de draagmoeder als vader op de geboorteakte vermeld had moeten staan. Als de wensouders dan bij de Nederlandse ambassade vragen om afgifte van een paspoort voor het kind of zich in Nederland bij de gemeente melden met het verzoek het kind in de daartoe bestemde registers in te schrijven, wordt een dergelijke aanvraag niet zelden afgewezen. Dit omdat de geboorteakte niet verenigbaar is met de Nederlandse openbare orde en daarom niet erkend kan worden. Het gevolg is dat het kind niet mee naar Nederland kan reizen respectievelijk het niet mogelijk is het kind te verzekeren bij een zorgverzekeraar, het te laten vaccineren en/of op een kinderdagverblijf in te schrijven. Het entameren van een gerechtelijke procedure is dan onvermijdbaar.

Op grond van artikel 10:100 BW wordt een in het buitenland tot stand gekomen onherroepelijke rechterlijke beslissing waarbij familierechtelijke betrekkingen uit hoofde van afstamming zijn vastgesteld of gewijzigd, in

4. Zie onder meer Rb. Amsterdam 12 februari 2020, ECLI:NL:RBAMS 2020:1628, Rb. Amsterdam 12 februari 2020, ECLI:NL:RBAMS 2020:871, Rb. Den Haag 13 januari 2020, ECLI:NL:RBDHA:2020:244 en Rb. Amsterdam 13 november 2019, ECLI:NL:RBAMS:2019:10097.

5. Mennesson v. France, no. 65192/11, ECHR 2014

6. No. P16-2018-001.
Nederland van rechtswege erkend, tenzij er voor de rechtsmacht van de rechter kennelijk onvoldoende aanknoping bestond met de rechtssfeer van diens land, aan die beslissing kennelijk geen behoorlijk onderzoek of behoorlijke rechtspleging is voorafgegaan, of de erkenning van die beslissing kennelijk onverenigbaar is met de openbare orde. In artikel 10:101 BW is voorts bepaald dat ook in het buitenland tot stand gekomen rechtsfeiten of rechtshandelingen waarbij familierechtelijke betrekkingen uit hoofde van afstamming zijn vastgesteld of gewijzigd en die zijn neergelegd in een door een bevoegde instantie overeenkomstig de plaatselijke voorschriften opgemaakte akte, hier van rechtswege worden erkend, tenzij hieraan geen behoorlijk onderzoek of behoorlijke rechtspleging is voorafgegaan, of de erkenning van die beslissing kennelijk onverenigbaar is met de openbare orde.

Veelal wordt er door de Ambtenaar van de Burgerlijke Stand een beroep gedaan op de 'tenzij-bepaling' omdat er volgens de ambtenaar geen behoorlijk onderzoek aan de geboorteakte is voorafgegaan of dat erkenning van de geboorteakte onverenigbaar is met de openbare orde. Indien de rechter in dat betoog meegaat, zullen de geboortegegevens van het kind opnieuw vastgesteld moeten worden voor het opstellen van een geboorteakte die wél in lijn is met de Nederlandse wet- en regelgeving (art. 1:25c lid 1 sub c BW). Inmiddels zien wij in de rechtspraak echter ook terug ${ }^{7}$ dat de rechter het beroep van de ambtenaar op de onverenigbaarheid met de openbare orde niet honoreert. De ambtenaar wordt dan alsnog bevolen de geboorteakte in te schrijven omdat het enkele feit dat het van rechtswege ontstaan van een familierechtelijke betrekking met de beide wensouders niet overeenstemt met (de huidige) bepalingen uit het Nederlandse recht, onvoldoende is om aan te nemen dat sprake is van onverenigbaarheid met de openbare orde. Van belang is daarbij ook hoe artikel 8 IVRK (het recht van het kind om te weten van wie het afstamt) is gewaarborgd en of een van beide ouders genetisch ouder is van het kind. Opmerkelijk is overigens dat de plannen van het kabinet om een regeling te treffen voor draagmoederschap eveneens worden meegewogen. Zo overwoog de rechtbank Amsterdam recent:

Gelet op het voorgaande is het door verzoekers doorlopen draagmoederschapstraject met voldoende waarborgen omkleed overeenkomstig de aanbevelingen van de Staatscommissie en het voornemen voor de te treffen draagmoederschapsregeling van het kabinet zoals verwoord in de brief van 12 juli 2019. De rechtbank is dan ook van oordeel dat in deze situatie geen sprake is van onverenigbaarheid met de openbare orde. $^{8}$

Hoewel enerzijds kritiek kan worden geuit op het feit dat de rechtspraak hiermee vooruitloopt op de wet-

7. Zie Rb. Amsterdam 12 februari 2020, ECLI:NL:RBAMS:2020:1628, r.o. 5.12 .

8. Zie Rb. Amsterdam 12 februari 2020, ECLI:NL:RBAMS:2020:1628, r.o. 5.12 
geving, is het anderzijds niet onbegrijpelijk. De wetgeving in Nederland loopt immers achter de feiten aan als het aankomt op draagmoederschap. Het ontbreken van een draagmoederschapsregeling in Nederland weerhoudt ouders met een sterke kinderwens er niet van alles in het werk te stellen om deze alsnog in vervulling te laten gaan. Hiermee worden rechters voor een voldongen feit geplaatst. Als procedures worden gestart, verblijft het kind doorgaans al bij de wensouders en heeft de draagmoeder bevestigd dat zij niet de wens heeft het kind zelf te verzorgen en op te voeden.

In de volgende paragraaf zullen wij kort schetsen wat het voornemen van de te treffen draagmoederschapsregeling inhoudt en wat dit betekent voor de rechtspraktijk.

\section{Wat gaat er veranderen?}

Het kabinet is zich ervan bewust geworden dat de samenleving verandert, alsmede de opvattingen over relaties en het ouderschap. Daarnaast zijn de medische (fertiliteits)mogelijkheden toegenomen om mensen met een kinderwens te helpen bij het stichten van een gezin. Het kabinet meent dat het voor alle betrokkenen wenselijk is om waar mogelijk voorafgaand aan de geboorte te waarborgen dat het traject van draagmoederschap zorgvuldig en transparant verloopt en zo veel mogelijk rechtszekerheid wordt geboden. Zoals reeds opgemerkt, is op 24 april 2020 het Concept Wetsvoorstel Kind online ter consultatie aangeboden. Op 22 mei 2020 is de consultatie gesloten. Op dit moment is er nog geen wetsvoorstel aanhangig bij de Tweede Kamer. In deze paragraaf wordt toegelicht hoe het wetsvoorstel er naar verwachting in grote lijnen uit zal komen te zien en beantwoorden wij de vraag of dit bijdraagt aan vereenvoudiging voor de rechtspraktijk.

Doel

Het wetsvoorstel heeft als doel de positie van alle betrokkenen bij draagmoederschap beter te beschermen. Met de regeling wordt voor het kind direct vanaf de geboorte duidelijk wie de juridische ouders zijn en wie de verantwoordelijkheid dragen voor de verzorging en opvoeding op de lange termijn. De voorgestelde regeling maakt het mogelijk dat de wensouders vanaf de geboorte worden angemerkt als de juridische ouders indien zij vóór de conceptie een gezamenlijk verzoek met de draagmoeder indienen bij de rechtbank. Wanneer de rechter dit verzoek tot gerechtelijke toekenning van ouderschap na draagmoederschap toewijst, worden de wensouders direct na de geboorteaangifte als juridische ouders van het kind op de geboorteakte vermeld. Ook zal de draagmoeder op het vervolgblad van de geboorteakte worden vermeld.

\section{Ontvankelijkheid}

Om onder de nieuwe regeling te vallen, moet ten minste een van de wensouders een genetische band hebben met het kind, behoudens uitzonderlijke gevallen. Hieronder valt bijvoorbeeld een medische onmogelijkheid. Daarnaast moet ten minste een van de wensouders én de draagmoeder in Nederland wonen, dienen zij de Nederlandse nationaliteit te hebben of dienen zij het recht te hebben op een permanent verblijf in Nederland.

\section{Verzoekschrift rechtbank voorafgaand de conceptie}

De voorgestelde regeling houdt in dat de wensouders - nog voordat de draagmoeder zwanger is - bij de rechtbank een verzoekschrift zullen indienen. Uit het verzoekschrift moet blijken dat de wensouders en de draagmoeder zich hebben laten voorlichten en laten adviseren, dat de financiële risico's van de draagmoeder zijn gedekt en dat er geen contra-indicaties bestaan voor de overdracht van het juridisch ouderschap. Het idee achter de voorlichting en de counseling is dat alle betrokken partijen weten waar ze aan beginnen en geinformeerde toestemming kunnen geven. Counseling en voorlichting moeten problemen tussen de draagmoeder en de wensouders zoveel mogelijk voorkomen. De algemene voorlichting ziet op informatie over het traject en de daarbij behorende voorwaarden en risico's die een rol spelen. Counseling ziet specifiek op medische, psychosociale en juridische aspecten van het traject. Voor juridische counseling kan doorverwezen worden naar gespecialiseerde advocaten. Medische en psychologische counseling dient plaats te vinden door BIG-geregistreerde psychologen op grond van de geldende beroepsstandaarden. Deze voorwaarde ziet zowel op hoog- als laagtechnologisch draagmoederschap. Wanneer er contra-indicaties uit de counseling naar voren komen, zullen deze opgenomen moeten worden in het verslag met betrekking tot de gevolgde voorlichting en daarmee worden overgelegd aan de rechter. Die kan daar vervolgens bij zijn beslissing rekening mee houden. ${ }^{9}$

Als bijlage bij het verzoekschrift dient een overeenkomst te worden overgelegd met daarin de afspraken tussen de draagmoeder en de wensouders, onder meer over het toekomstige contact tussen de draagmoeder en het kind. Het verzoekschrift bevat het verzoek om toekenning van het ouderschap na draagmoederschap. De rechtbank toetst zowel aan het belang van het kind dat wordt geboren uit draagmoederschap als aan de vrije instemming van de draagmoeder. De rechter dient te beoordelen of:

- er een door alle betrokkenen ondertekende draagmoederschapsovereenkomst is overgelegd dat bepaalde in de wet vastgelegde informatie bevat; - uit de draagmoederschapsovereenkomst blijkt dat ten minste een van de wensouders de genetische ouder van het kind zal zijn, tenzij de onmogelijkheid hiervan aannemelijk is gemaakt;

- uit de draagmoederschapsovereenkomst of anderszins blijkt dat de draagmoeder niet meer dan een (on)kostenvergoeding zal worden uitgekeerd;

9. MvT bij Concept Wetsvoorstel Kind, draagmoederschap en afstamming, p. 12 
- niet blijkt van een afhankelijkheidsrelatie die de vrije instemming van de draagmoeder negatief kan beïnloeden;

- de vrijwillige instemming van alle betrokkenen uit het verzoek blijkt;

- er contra-indicaties blijken uit de counseling of, bij het ontbreken van een verklaring omtrent het gedrag van de wensouders, het advies van de raad voor de kinderbescherming;

- de draagmoeder ter zitting verklaart nog niet zwanger te zijn van het kind;

- het draagmoederschap anderszins niet in het belang van het kind moet worden geacht;

- de draagmoeder en ten minste een van de wensouders de gewone verblijfplaats hebben in Nederland, en

- de draagmoeder en ten minste een van de wensouders de Nederlandse nationaliteit hebben dan wel rechtmatig verblijf in Nederland hebben. ${ }^{10}$

Wanneer het kind wordt geboren, zullen de wensouders vanaf de geboorte als juridische ouders op de geboorteakte komen te staan. De draagmoeder kan echter wel tot een korte periode na de geboorte de rechter verzoeken de draagmoederschapsovereenkomst te ontbinden en de erkenningsakte(n) van de wensouders te laten doorhalen.

\section{Financiële vergoeding}

Hoewel commercieel draagmoederschap verboden blijft, komt er wel een (on)kostenvergoeding voor de draagmoeder. Te denken valt aan de reiskosten die de draagmoeder maakt om naar het ziekenhuis/verloskundige te reizen, een vergoeding voor de dagen die zij niet kan werken en een dekking van medische kosten die niet onder haar zorgverzekering vallen.

Verder is het streven dat wensouders en vrouwen die als draagmoeder voor een ander een kind willen krijgen, bij één centrale instantie terechtkunnen. Met de mogelijkheid voor draagmoeders om zich ergens te kunnen melden wanneer zij uit ideële overwegingen een kind willen dragen voor een ander, hoopt de minister te voorkomen dat wensouders naar het buitenland vertrekken. Deze zogenoemde 'draagmoederschapsbank' mag echter geen winstoogmerk hebben.

Waarborg van kennis van ontstaansgeschiedenis Met de voorgestelde regeling wil de wetgever garanderen dat het voor het kind mogelijk moet zijn om op termijn zijn ontstaansgeschiedenis te achterhalen. Dit betekent dat het kind te weten moet kunnen komen wie de draagmoeder, alsmede wie de eventuele zaad- of eiceldonor is geweest. Omdat deze informatie altijd makkelijk te vinden moet zijn, is het voorstel dat hiervoor één loket komt, waar alle beschikbare informatie over identiteit en oorsprong is op te vragen. ${ }^{11}$

10. MvT bij Concept Wetsvoorstel Kind, draagmoederschap en afstamming, p. 13

11. MvT bij Concept Wetsvoorstel Kind, draagmoederschap en afstamming, p. 1
Regeling voor buitenlands draagmoederschap Door de minister wordt erkend dat het hebben van een Nederlandse regeling niet voorkomt dat er vraag blijft naar buitenlands draagmoederschap. Zoals uit de vorige paragraaf blijkt, levert buitenlands draagmoederschap uitdagingen op voor de Nederlandse rechtspraktijk. De minister heeft laten weten dat buitenlands draagmoederschap toegankelijk blijft, mits het overeenkomt met de belangrijkste uitgangspunten van de Nederlandse regelgeving. Voor zowel wensouders als uitvoeringsinstanties moet met de nieuwe regeling duidelijk worden welke buitenlandse wegen niet geaccepteerd worden en welke wegen wel voor erkenning in aanmerking komen. Om die reden zal er ook voor buitenlands draagmoederschap een regeling worden getroffen die meebrengt dat het in het buitenland ontstane ouderschap in Nederland zal worden erkend. Hoe deze regeling eruit komt te zien, is nog niet bekend. Wel is bekend dat deze regeling gebaseerd zal worden op de internationale jurisprudentie op dit terrein. ${ }^{12}$ Duidelijk moet worden wanneer een buitenlandse geboorteakte na draagmoederschap in ieder geval níet voor eenvoudige erkenning in aanmerking komt. ${ }^{13}$ Bijvoorbeeld wanneer:

- niet vaststaat dat het kind genetisch verwant is aan ten minste een van de wensouders;

- de gegevens over de afstamming voor het kind niet achterhaalbaar zijn of binnen een redelijke termijn achterhaalbaar zullen worden;

- er geen rechterlijke beslissing ten grondslag ligt aan de buitenlandse geboorteakte van een kind geboren uit draagmoederschap;

- voor zover het ouderschap van de wensouders vóór de geboorte is ontstaan, er na de geboorte geen mogelijkheid voor de draagmoeder heeft bestaan om een beroep te doen op de rechter om het ouderschap te betwisten. ${ }^{14}$

De minister benadrukt dat voorlichting aan wensouders over deze voorwaarden prioriteit krijgt. Onzes inziens is dat van groot belang. Wensouders zijn zich niet altijd bewust van de (strafrechtelijke) gevolgen die draagmoederschap in het buitenland met zich brengt. Met goede voorlichting weten wensouders dat kiezen voor een land dat niet voldoet aan de Nederlandse voorwaarden een lange periode van onzekerheid betekent, vooral voor het kind. Zo zal niet zeker zijn of het kind tot Nederland toegelaten zal worden, hier langdurig zal mogen verblijven en of het juridisch ouderschap van de wensouders wordt erkend. Wanneer wensouders desalniettemin voor een buitenlandse draagmoederschapstraject kiezen, aanvaarden zij daarmee de aanmerkelijke kans dat dit uitmondt in kostbare en tijdrovende juridische procedures waarvan de uitkomst onzeker is.

12. Wij verwijzen hierbij naar de hiervoor genoemde advisory opinion van het EHRM d.d. 10 april 2019, No. P16-2018-001

13. Kamerstukken II 2018/19, 33836, nr. 45, d.d. 12 juli 2019

14. MvT bij Concept Wetsvoorstel Kind, draagmoederschap en afstamming, p. 16. 


\section{Conclusie}

Voor de familierechtpraktijk is het van toegevoegde waarde dat er een regeling voor draagmoederschap komt. Vooralsnog dienen advocaten creatief om te gaan met de regelgeving die er wel is en de rechtspraak die met de jaren gevormd is om het beoogde eindresultaat voor de wensouders te bereiken: de juridische werkelijkheid in overeenstemming brengen met de feitelijke werkelijkheid. Het ontbreken van een duidelijke regeling leidt tot onrust en onzekerheid bij wensouders, die doorgaans al verscheidende jaren emotioneel belast zijn met de onmogelijkheid om op natuurlijke wijze een kind te krijgen. Wij menen dat het in hun belang en in het belang van het kind is dat er na de geboorte direct duidelijkheid is en er geen complexe (en onzekere) juridische procedures meer hoeven te worden doorlopen. De komst van een draagmoederschapsregeling neemt echter niet weg dat het voor wensouders en draagmoeders van groot belang blijft zich tijdig te laten informeren en adviseren over de gevolgen en risico's van draagmoederschap. Zo zullen zij onder meer moeten nadenken over wat de rol van de draagmoeder zal zijn in de toekomst. Soms wenst de draagmoeder betrokken te worden bij de opvoeding van het kind. Het is dan belangrijk dat de verwachtingen en grenzen helder naar elkaar worden gecommuniceerd om op een later moment conflicten hierover te voorkomen. De plicht om - nog voordat de draagmoeder zwanger is - een verzoekschrift bij de rechtbank in te dienen met daarin de vermelding hoe de wensouders en draagmoeder zijn voorgelicht en geadviseerd, draagt hier zeker aan bij.

Voorts is het positief te lezen dat er een heldere richtlijn komt over de erkenning van buitenlandse geboorteakten in Nederland. Hiermee wordt voorkomen dat ouders met hun kind naar Nederland terugreizen en hier voor verrassingen komen te staan. Voor de familierechtadvocaat blijft evenwel de belangrijke taak weggelegd om wensouders voorafgaand aan de conceptie voor te lichten over de stappen die voorafgaand en ná de geboorte doorlopen moeten worden. Zo weten wensouders wat hen te wachten staat en hoeven zij zich minder zorgen te maken over de juridische zaken. Ligt er voor hen nog één taak weggelegd, uitkijken naar het moment dat hun diepgewortelde wens eindelijk werkelijkheid wordt: de komst van hun kind. 